\title{
The association between chiropractors' view of practice and patient encounter-level characteristics in Ontario, Canada: a cross-sectional study
}

Jessica J. Wong ${ }^{1,2,3^{*}}$, Sheilah Hogg-Johnson ${ }^{1,2,4}$, André E. Bussières ${ }^{5,6}$, Simon D. French ${ }^{7}$ and Silvano A. Mior ${ }^{1,2,4}$

\begin{abstract}
Background: Chiropractors have diverse views of practice, but the impact on their patient profiles and treatment approaches remains unclear. We assessed the association between chiropractors'view of practice (unorthodox versus orthodox) and patient encounter-level characteristics among chiropractors who practice in Ontario, Canada.

Methods: We conducted a cross-sectional study using Ontario Chiropractic Observation and Analysis STudy (O-COAST) data. In O-COAST, Ontario chiropractors were randomly recruited from a list of registered chiropractors in 2015 and recorded up to 100 consecutive patient encounters. We classified chiropractors' response regarding their views of practice as unorthodox when viewing "vertebral subluxation as an encumbrance to health that is corrected to benefit overall well-being"; other views were considered orthodox. Patient encounter-level characteristics included: (1) non-musculoskeletal reason-for-encounter; (2) subluxation as diagnosis; (3) duration of encounter (logtransformed for modeling); (4) unimodal manipulative treatment; and (5) patient health characteristics (good health status, some activity limitations). We conducted multilevel logistic regression to assess the association between view of practice and aforementioned characteristics, accounting for potential confounders and clustering of encounters within chiropractors. The multilevel models had two levels (level 1-patient encounter level; level 2-chiropractor level), with level 1 patient encounters nested within level 2 chiropractors.
\end{abstract}

Results: We included 40 chiropractors (mean age $=43.4$ years, $S D=11.5$ ) and 3,378 chiropractor-patient encounters. The 2,332 unique patients identified had a mean age of 48.5 years $(S D=18.5)$. Chiropractors with unorthodox views had higher odds of having patients with a non-musculoskeletal reason-for-encounter (adjusted odds ratio (aOR) 16.5, 95\% Cl 3.2-84.0) and subluxation as diagnosis (aOR 63.0, 95\% Cl 4.2-949.1). Encounters of chiropractors with unorthodox views were 0.6 times shorter than those with orthodox views (95\% Cl 0.4-0.9). Chiropractor level explained 32\%, $75 \%$, and $49 \%$ of the variability in non-musculoskeletal reason-for-encounter, subluxation as diagnosis, and encounter duration, respectively. We observed no association between unorthodox view and unimodal manipulative treatment or patient health characteristics.

\footnotetext{
*Correspondence: jessica.wong@ontariotechu.ca

${ }^{1}$ Institute for Disability and Rehabilitation Research, Ontario Tech

University and Canadian Memorial Chiropractic College, 2000 Simcoe

Street North, Oshawa, ON L1G 0C5, Canada

Full list of author information is available at the end of the article
}

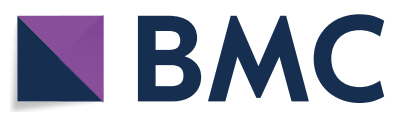

(c) The Author(s) 2021. Open Access This article is licensed under a Creative Commons Attribution 4.0 International License, which permits use, sharing, adaptation, distribution and reproduction in any medium or format, as long as you give appropriate credit to the original author(s) and the source, provide a link to the Creative Commons licence, and indicate if changes were made. The images or other third party material in this article are included in the article's Creative Commons licence, unless indicated otherwise in a credit line to the material. If material is not included in the article's Creative Commons licence and your intended use is not permitted by statutory regulation or exceeds the permitted use, you will need to obtain permission directly from the copyright holder. To view a copy of this licence, visit http://creativecommons.org/licenses/by/4.0/. The Creative Commons Public Domain Dedication waiver (http://creativeco mmons.org/publicdomain/zero/1.0/) applies to the data made available in this article, unless otherwise stated in a credit line to the data. 
Conclusions: Chiropractors' unorthodox view of practice was associated with treating non-musculoskeletal conditions, subluxation as diagnosis, and shorter duration of encounter. Chiropractor level explained a high proportion of variability in these outcomes. Findings have implications for understanding chiropractic practice and informing interprofessional collaboration.

Keywords: Chiropractic, View of practice, Patient characteristics, Treatment characteristics, Cross-sectional study

\section{Background}

Chiropractic is a healthcare profession concerned with the management of musculoskeletal conditions, and a commonly used complementary and alternative medicine therapy [1-3]. Chiropractors practice in more than 100 countries worldwide, with the largest distribution in the United States and Canada [4]. A recent scoping review reported that the median 12-month utilization of chiropractic services was $9.1 \%$ (interquartile range (IQR) 6.7-13.1\%) globally [5]. The most common reasons for people attending chiropractic care are low back pain, neck pain, and extremity problems [5]. The most common treatments provided by chiropractors include spinal manipulation, soft tissue therapy, and education [5]. Across health systems, chiropractors provide care to a considerable proportion of patients with musculoskeletal conditions [6], playing an important role in their management in the primary care setting.

Chiropractors have diverse views of practice related to the health conditions that they treat. Some chiropractors have an unorthodox view, considered as viewing spinal dysfunctions, termed 'vertebral subluxations', as an encumbrance to the expression of health that is corrected to benefit overall patient well-being [7]. This view of practice perceives vertebral subluxations as a negative effect on the body's innate ability to heal, which can be corrected through spinal manipulation [8-10]. The majority (approximately $70-80 \%$ ) of chiropractors do not endorse this unorthodox view and provide evidencebased care for the management of musculoskeletal conditions [7, 11-15]. However, previous studies estimated that between $19 \%$ to $28 \%$ of chiropractors have an unorthodox view of practice $[7,14,15]$. Specifically, McGregor et al. reported that $19 \%$ of Canadian chiropractors in 2014 had an unorthodox view of practice [7]. Biggs et al. reported that $28 \%$ of Canadian chiropractors in 2002 were considered empiricists, which aligned with an unorthodox perspective and relied on clinical experience as the main method for validating chiropractic [14]. In the United States, McDonald et al. surveyed a random sample of chiropractors in North America in 2004 [15] and found that $5 \%$ of chiropractors aligned with an unorthodox view, while $24 \%$ reported a middle scope, which tended to combine spinal manipulation of subluxations with other management approaches [15].
It remains unclear to what extent the unorthodox view among some chiropractors influences their patient profiles and treatment approaches. McGregor et al. reported that an unorthodox view of practice among chiropractors was associated with non-evidence-based treatment choices, use of radiographs that was not consistent with evidence-based guidelines, and a negative attitude towards vaccination [7]. Previous literature also suggests that unorthodox views are associated with treatment of non-musculoskeletal conditions [15, 16]. However, studies are needed to assess whether unorthodox views are associated with differences in other patient encounter-level characteristics, including diagnosis, treatment provided, and patient health characteristics. Understanding the patient profiles and treatment approaches of chiropractors with varying views could greatly advance our understanding of chiropractic practice and inform collaboration among chiropractors and other healthcare providers. Describing whether patient profiles and treatment approaches vary by chiropractors with different views on practice provides a more comprehensive perspective of chiropractic care. In turn, understanding these characteristics would guide collaboration and communication between chiropractors and other healthcare providers. This can inform decision-making on referrals or comanagement with other healthcare providers, based on a better understanding of the needs and characteristics of chiropractic patients and chiropractic care delivered.

Therefore, the objective of this study was to assess the association between chiropractors' view of practice (unorthodox versus orthodox) and patient encounterlevel characteristics among chiropractors who practice in Ontario, Canada.

\section{Methods}

We conducted a cross-sectional study using data from the Ontario Chiropractic Observation and Analysis STudy (O-COAST) [17]. We reported this study according to the Strengthening the Reporting of Observational Studies in Epidemiology statement [18]. This project has been approved by the Research Ethics Board at the Canadian Memorial Chiropractic College (REB \#1404X03). 


\section{Study sample and data source}

Eligible for the study were chiropractor participants of O-COAST within the primary care setting in Ontario, Canada. We excluded chiropractor participants with missing data on view of practice (1 chiropractor) and those with data errors (1 chiropractor). In O-COAST, chiropractors were randomly recruited from a list of 3,978 chiropractors registered with the College of Chiropractors of Ontario in 2014. Chiropractors in active clinical practice (full-time, part-time, or locum) in Ontario were eligible to participate. Each chiropractor invited consecutive patients to participate until 100 encounters were recorded per chiropractor, or when four weeks of recording elapsed. A total of 135 randomly selected chiropractors were approached, of which 120 chiropractors were eligible, and 43 agreed to participate (36\% response rate). One chiropractor withdrew due to personal reasons and 42 completed the study ( $98 \%$ follow-up rate). The 43 chiropractor participants provided information on 3,523 chiropractor-patient encounters between July 3, 2014 and July 15, 2015. No direct identifiers were collected from the chiropractor. Information on patients was kept confidential by the research team. Re-identification of individuals is not be possible, since only aggregate findings are reported. Additional details on O-COAST methods are available in the published study [17].

Ontario is the largest province by population $(\sim 14.6$ million in 2020) in Canada [19]. A chiropractor in Ontario is a member of a regulated health profession, regulated by the College of Chiropractors of Ontario under the Regulated Health Professions Act, 1991 [20]. Doctors of chiropractic complete a minimum of 7 years of post-secondary education before becoming registered with College of Chiropractors of Ontario [20]. Chiropractic services are not paid through the government-run provincial health insurance plan, which is the Ontario Health Insurance Plan. Fees for chiropractic services may be out-of-pocket or paid by extended health insurance, workers' compensation for occupational injuries, or automobile insurance for traffic-related injuries.

\section{Main independent variable: chiropractors' view of practice}

We defined chiropractors' view of practice based on a single question with six statements that best describes their predominant view of the conditions treated (Additional File 1) [7]. Responses to the six statements were dichotomized with those viewing vertebral subluxation as an encumbrance to the expression of health that is corrected to benefit patient well-being classified as unorthodox. All other views were classified as orthodox. This question was validated by McGregor et al. [7] and used in studies to define view of practice among chiropractors [21].

Dependent variables: patient encounter-level characteristics

We estimated the direction and magnitude of the association between chiropractors' view of practice and patient encounter-level characteristics. As informed by previous literature [7, 14-16, 22], the following dependent variables were selected a priori:

1. Reason for encounter for a non-musculoskeletal condition (non-musculoskeletal versus other). Informed by previous literature [17], the list of non-musculoskeletal conditions was defined by the authors and included visceral (e.g., digestive, ear, eye, respiratory, skin, urology, circulatory, endocrine and metabolic conditions) and psychological conditions (Additional File 2).

2. Subluxation as diagnosis (subluxation versus other)

3. Duration of patient encounter (continuous variable in minutes)

4. Unimodal manipulative treatment i.e., one intervention only (manual adjustment and/or chiropractic system versus other)

5. In subset of data due to data availability:

- Very good/satisfied health status (i.e., self-rated general health of patient as excellent health/very good, and quality of life as very good, and satisfaction with health as very satisfied/satisfied)

- Activity limitations (none, a few, versus some)

Very good/satisfied health status was defined as a composite measure of three variables, which were self-rated general health, quality of life, and satisfaction with health. Self-rated general health was based on the question, "In general, would you say your health is excellent, very good, good, fair, or poor?" (excellent/very good versus $\operatorname{good} /$ fair/poor). Self-rated quality of life was based on the question, "How would you rate your quality of life" (very good versus good/neither poor nor good/poor/very poor). Self-rated satisfaction with life was based on the question, "How satisfied are you with your health?" (very satisfied/satisfied versus neither satisfied nor unsatisfied/ fairly dissatisfied/dissatisfied). Activity limitations was based on the question, "how many activities does your pain or discomfort prevent?" (none/a few versus some).

\section{Covariates}

We included the following patient encounter-level variables as covariates in the models: age (in years); sex (men, women); number of comorbidities ( $0,1,2$ or more), and imaging undertaken (yes, no). We identified other 
potential confounders using the model building approach outlined in the analysis section.

\section{Analysis}

We described the chiropractor participants with respect to sociodemographic, education, and practice-related factors using means [standard deviations (SD)] or medians [interquartile ranges (IQR)] and percentages for continuous and categorical variables, respectively, stratified by chiropractors' view of practice. Similarly, we described the patient encounters with respect to sociodemographic, treatment- and health-related factors, stratified by chiropractors' view of practice.

We conducted multilevel logistic regression models to assess the association between chiropractors' view of practice and the aforementioned patient encounter-level characteristics, accounting for clustering of encounters within chiropractors. The multilevel regression models had two levels (level 1-the patient encounter, level 2the chiropractor), with level 1 patient encounters nested within level 2 chiropractors. The main independent variable, view of practice, is measured at the chiropractor level, while covariates and outcomes are measured at the patient encounter level. The variance explained by chiropractor level is that explained by both unorthodox/ orthodox view of practice and the random intercept. We adjusted for potential confounders in the models, which included confounders determined conceptually and those selected using a model building strategy to assess for a $10 \%$ change in the exposure regression coefficient. Variables that led to a $10 \%$ change in the exposure regression coefficient were new patient encounter (yes, no), extended health insurance as payment method (yes, no), injury related to motor vehicle collision (yes, no), and injury related to workers' compensation (yes, no); therefore, these variables were included in the fully adjusted models. We used a link function in the analysis for duration of patient encounter (log-transformed) to account for skewed distributions. The analysis for this study was generated using SAS software, version 9.4. of the SAS System for Windows (Copyright $\odot$ 2002-2012, SAS Institute Inc., Cary, NC, USA. SAS and all other SAS Institute Inc. product or service names are registered trademarks or trademarks of SAS Institute Inc., Cary, NC, USA.)

We conducted sensitivity analyses to explore the impact of potential misclassification of the chiropractors' view of practice as described by McGregor et al. [7]. First, we conducted a sensitivity analysis by redefining unorthodox view by those who predominantly view treating vertebral subluxation as unorthodox (i.e., combining those who "treat vertebral subluxation as an encumbrance to the expression of health" and "treat vertebral subluxation as a somatic joint dysfunction and/or related to functional or musculoskeletal problems") versus all other views defined as orthodox. Second, we dichotomized to chiropractors who predominantly view treating "vertebral subluxations" (i.e., the two aforementioned responses) or "lifestyle and wellness issues", compared to all other views redefined as orthodox.

\section{Results}

The O-COAST data had a total of 42 chiropractor participants and 3,523 chiropractor-patient encounters; we excluded 1 chiropractor due to missing exposure data and 1 chiropractor due to data errors (Fig. 1). Therefore, 40 chiropractor participants and 3378 chiropractorpatient encounters were used for analysis. Of the 3378 encounters, we identified 2332 unique patients (with complete data on date of birth and postal code).

\section{Chiropractor characteristics}

The 40 chiropractors had a mean age of 43.4 years (SD 11.5 ) and median 12.5 years in practice (IQR 6.0-24.0), with 33\% women (Table 1). There were 32 (80\%) chiropractors with an orthodox view of practice, and $8(20 \%)$ who had an unorthodox view. Chiropractors with an unorthodox view of practice had a higher number of patient visits per week (median 135.0, IQR 72.5-197.5) than those with orthodox views (median 70.0, IQR 30.0116.0). A higher proportion of chiropractors with an unorthodox view had imaging services available within the premises of their clinic than chiropractors with orthodox views (50\% versus $3 \%$ ).

\section{Patient characteristics}

The 2,332 unique patients had a mean age of 48.5 years (SD 18.5), with $58.4 \%$ female and $16.2 \%$ living in a rural area (Table 2). A lower proportion of patients receiving care from chiropractors with an unorthodox view had extended private health insurance than those seeing chiropractors with orthodox views (3.7\% versus $41.6 \%$ ).

\section{Clinical encounter characteristics}

A higher proportion of patients seeing chiropractors with an unorthodox view had subluxation as a diagnosis (74.4\% versus $20.8 \%$ ) and received unimodal manipulative treatment $(12.4 \%$ versus $0.4 \%)$ than chiropractors with an orthodox view of practice (Table 2). Patients receiving care from chiropractors with an unorthodox view had shorter durations of encounter (median $10 \mathrm{~min}$, IQR 7-14) compared to those with orthodox views (median 15 min, IQR 10-30). 


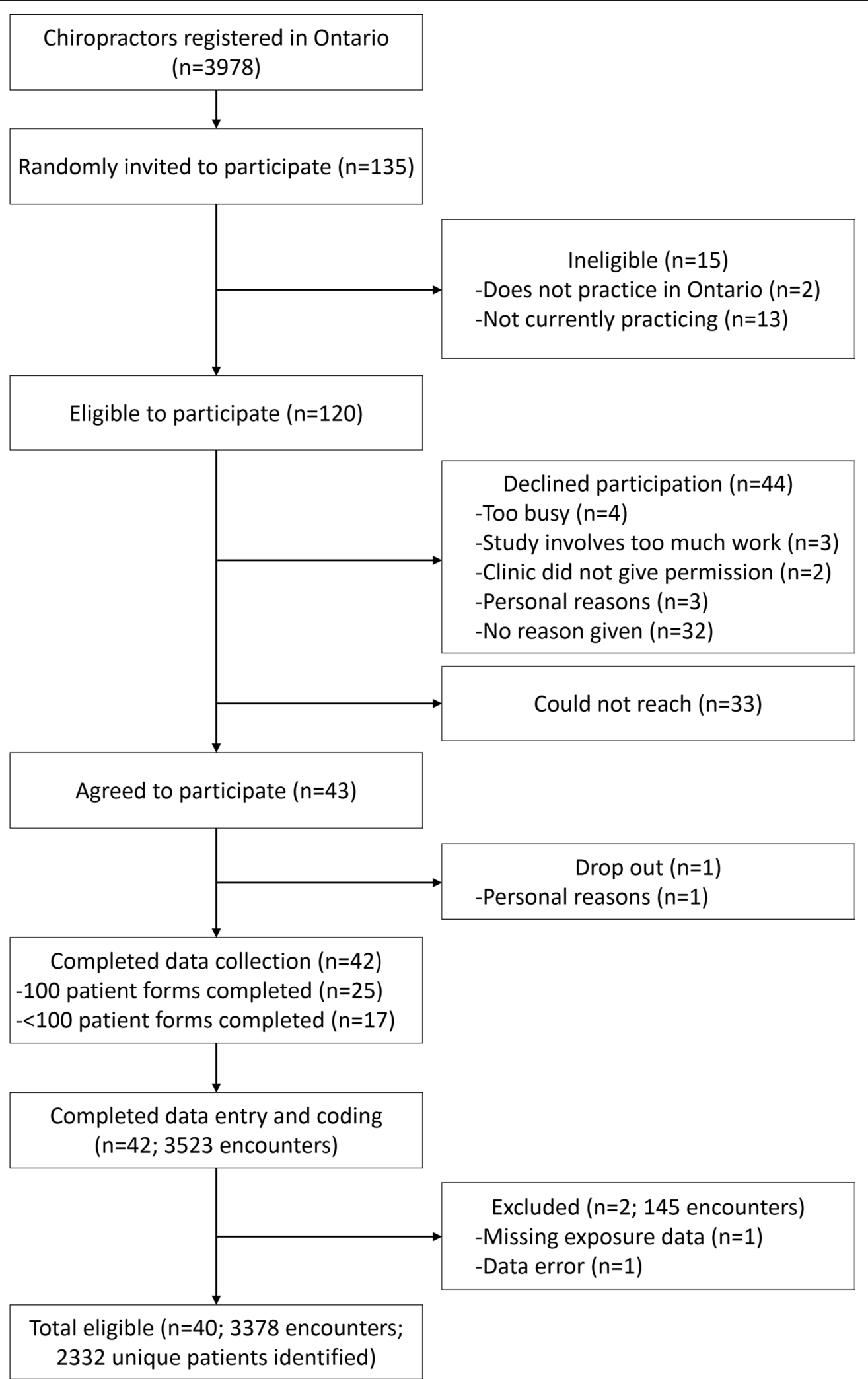

Fig. 1 Flow diagram for the enrolment of chiropractors and data collection for the Ontario Chiropractic Observation and Analysis STudy (O-COAST) 
Table 1 Characteristics of chiropractors participating in O-COAST by view of chiropractic practice ${ }^{a}(n=40)$

\begin{tabular}{|c|c|c|c|}
\hline & All chiropractors $(n=40)$ & $\begin{array}{l}\text { Unorthodox view of } \\
\text { practice }^{a}(n=8)\end{array}$ & $\begin{array}{l}\text { Orthodox view of } \\
\text { practice }(n=32)\end{array}$ \\
\hline \multicolumn{4}{|l|}{ Chiropractor characteristics ${ }^{\mathrm{b}}$} \\
\hline Women & $13(32.5 \%)$ & $3(37.5 \%)$ & $10(31.3 \%)$ \\
\hline Age in years, median (IQR) & $41.5(36.0-52.5)$ & $43.5(39-54.5)$ & $41.0(34.0-50.5)$ \\
\hline Years in practice, median (IQR) & $12.5(6.0-24.0)$ & $13.5(8.0-28.0)$ & $12.5(6.0-20.5)$ \\
\hline Years since graduation, median (IQR) & $14.0(7.0-27.0)$ & $14.0(8.5-28.5)$ & $14.0(7.0-24.5)$ \\
\hline \multicolumn{4}{|l|}{ Country of graduation } \\
\hline Canada & $33(82.5 \%)$ & $7(87.5 \%)$ & $26(81.3 \%)$ \\
\hline USA & $6(15.0 \%)$ & $0(0 \%)$ & $6(18.8 \%)$ \\
\hline Other & $1(2.5 \%)$ & $1(12.5 \%)$ & $0(0 \%)$ \\
\hline Holds postgraduate qualification & $7(18.4 \%)$ & $1(14.3 \%)$ & $6(19.4 \%)$ \\
\hline \multicolumn{4}{|l|}{ Practice characteristics ${ }^{b}$} \\
\hline Number of patient visits per week, median (IQR) & $80.0(32.5-150.0)$ & $135.0(72.5-197.5)$ & $70.0(30.0-116.0)$ \\
\hline \multicolumn{4}{|l|}{ Number of chiropractors at practice } \\
\hline Solo practitioner & $21(52.5 \%)$ & $2(25.0 \%)$ & $19(59.4 \%)$ \\
\hline Other chiropractor(s) at practice & $19(47.5 \%)$ & $6(75.0 \%)$ & $13(40.6 \%)$ \\
\hline $\begin{array}{l}\text { Other non-chiropractic healthcare practitioner available at } \\
\text { same premises }\end{array}$ & $31(77.5 \%)$ & $7(87.5 \%)$ & $24(75.0 \%)$ \\
\hline Imaging services available at same premises & $5(12.0 \%)$ & $4(50.0 \%)$ & $1(3.1 \%)$ \\
\hline Paper-only clinical records & $22(55.0 \%)$ & $4(50.0 \%)$ & $18(56.3 \%)$ \\
\hline \multicolumn{4}{|l|}{ Type of practice } \\
\hline General/family & $33(82.5 \%)$ & $7(87.5 \%)$ & $26(81.3 \%)$ \\
\hline Sports/rehabilitation & $5(12.5 \%)$ & $1(12.5 \%)$ & $5(15.6 \%)$ \\
\hline Wellness/lifestyle counselling & $2(5.0 \%)$ & $0(0 \%)$ & $1(3.1 \%)$ \\
\hline
\end{tabular}

IQR interquartile range; O-COAST Ontario Chiropractic Observation and Analysis STudy

${ }^{a}$ Unorthodox view of practice defined as viewing vertebral subluxation as an encumbrance to the expression of health that is corrected to benefit patient well-being

${ }^{\mathrm{b}}$ Number (\%) of chiropractors unless otherwise specified

\section{Association between unorthodox view of practice and patient encounter-level characteristics}

Based on fully adjusted analyses, chiropractors with an unorthodox view of practice had higher odds of having patients with a non-musculoskeletal reason for encounter (adjusted odds ratio $(\mathrm{aOR})=16.5,95 \%$ CI 3.2-84.0) and subluxation as diagnosis $(\mathrm{aOR}=63.0,95 \% \mathrm{CI} 4.2-$ 949.1) (Table 3). The encounters of chiropractors with an unorthodox view were 0.6 times shorter than those with orthodox views (95\% CI 0.4-0.9). Chiropractor level explained $31.5 \%, 75.4 \%$, and $48.7 \%$ of the variability in non-musculoskeletal reason for encounter, subluxation as diagnosis, and duration of encounter, respectively.

We observed no association between unorthodox view and unimodal manipulative treatment (Table 3) or patient health characteristics (i.e., some activity limitations or excellent/very good health status) based on fully adjusted analyses (Table 4). Chiropractor level explained $10.0 \%$ and $7.7 \%$ of the variability in some activity limitations and excellent/very good health status, respectively.

\section{Sensitivity analyses \\ Unorthodox view when defined as predominantly treating subluxations (combining two response options)}

Based on fully adjusted analyses, association between unorthodox view and non-musculoskeletal reason for encounter, subluxation as diagnosis, or duration of encounter was attenuated, but the association remained (Additional File 3a-d). Chiropractor level explained a high proportion of the variability in these outcomes. We observed no association between unorthodox view and unimodal manipulative treatment or patient health characteristics, similar to primary analyses.

\section{Unorthodox view when defined as predominantly treating subluxations or lifestyle and wellness issues}

Association between unorthodox view and non-musculoskeletal reason-for-encounter or duration of encounter was attenuated, but the association remained based on fully adjusted analyses (Additional File $4 \mathrm{a}-\mathrm{d}$ ). Chiropractor level explained a high proportion of the variability in these outcomes. The association between unorthodox view and subluxation as diagnosis was greater compared 
Table 2 Characteristics of unique patients in encounters as recorded by chiropractors by view of practice $(n=2,332)$

\begin{tabular}{|c|c|c|c|}
\hline Patient Characteristics $^{\mathrm{b}}$ & All patients $(n=2332)$ & $\begin{array}{l}\text { Unorthodox view of } \\
\text { practice }^{a}(n=565)\end{array}$ & $\begin{array}{l}\text { Orthodox view of } \\
\text { practice }(n=1767)\end{array}$ \\
\hline Women & $1362(58.4 \%)$ & $345(61.1 \%)$ & $1017(57.6 \%)$ \\
\hline Age in years, mean (SD) & $48.5(18.5)$ & $47.0(19.7)$ & $48.9(18.0)$ \\
\hline \multicolumn{4}{|l|}{ Age categories, in years ${ }^{c}$} \\
\hline$<15$ & $101(4.4 \%)$ & $33(5.9 \%)$ & $68(3.9 \%)$ \\
\hline $15-24$ & $163(7.0 \%)$ & $51(9.2 \%)$ & $111(6.3 \%)$ \\
\hline $25-44$ & $627(27.1 \%)$ & $138(24.8 \%)$ & $489(27.9 \%)$ \\
\hline $45-64$ & $966(41.8 \%)$ & $216(38.9 \%)$ & $750(42.7 \%)$ \\
\hline $65-74$ & $299(12.9 \%)$ & $84(15.1 \%)$ & $215(12.3 \%)$ \\
\hline$\geq 75$ & $156(6.8 \%)$ & $34(6.1 \%)$ & $122(6.9 \%)$ \\
\hline Rural location of residence & $378(16.2 \%)$ & $98(17.4 \%)$ & $280(15.9 \%)$ \\
\hline Non-English speaking background & $93(4.1 \%)$ & $25(4.6 \%)$ & $68(3.9 \%)$ \\
\hline Identifies as Aboriginal/Indigenous & $2(0.1 \%)$ & $0(0 \%)$ & $2(0.1 \%)$ \\
\hline \multicolumn{4}{|l|}{ Employment status } \\
\hline Employed & $1377(64.0 \%)$ & $316(62.5 \%)$ & $1061(64.5 \%)$ \\
\hline Home duties & $102(4.7 \%)$ & $51(2.6 \%)$ & $89(5.4 \%)$ \\
\hline Retired & $460(21.4 \%)$ & $216(21.2 \%)$ & $353(21.5 \%)$ \\
\hline Student & $196(9.1 \%)$ & $84(13.2 \%)$ & $129(7.8 \%)$ \\
\hline Unemployed/non-employed & $17(0.8 \%)$ & $3(0.6 \%)$ & $14(0.9 \%)$ \\
\hline \multicolumn{4}{|l|}{ Source of encounter payment } \\
\hline \multicolumn{4}{|l|}{ Workplace safety and insurance board } \\
\hline Yes & $21(0.9 \%)$ & $2(0.4 \%)$ & $19(1.1 \%)$ \\
\hline No & $2268(99.1 \%)$ & $542(99.6 \%)$ & $1726(98.9 \%)$ \\
\hline \multicolumn{4}{|l|}{ Motor vehicle accident ${ }^{c}$} \\
\hline Yes & $65(2.8 \%)$ & $9(1.7 \%)$ & $56(3.2 \%)$ \\
\hline No & $2224(97.2 \%)$ & $535(98.4 \%)$ & $1689(96.8 \%)$ \\
\hline \multicolumn{4}{|l|}{$V^{2}$ eterans affairs ${ }^{c}$} \\
\hline Yes & $10(0.4 \%)$ & $1(0.2 \%)$ & $9(3.2 \%)$ \\
\hline No & $2279(99.6 \%)$ & $543(99.8 \%)$ & $1736(96.8 \%)$ \\
\hline \multicolumn{4}{|l|}{ Extended private health insurance ${ }^{c}$} \\
\hline Yes & $746(32.6 \%)$ & $20(3.7 \%)$ & $726(41.6 \%)$ \\
\hline No & $1543(67.4 \%)$ & $524(96.3 \%)$ & $1019(58.4 \%)$ \\
\hline \multicolumn{4}{|l|}{ Patient paid ${ }^{c}$} \\
\hline Yes & $1567(68.5 \%)$ & $418(76.8 \%)$ & $1149(65.9 \%)$ \\
\hline No & $722(31.5 \%)$ & $126(23.2 \%)$ & $596(34.2 \%)$ \\
\hline \multicolumn{4}{|l|}{ No charge $e^{c}$} \\
\hline Yes & $59(2.6 \%)$ & $25(4.6 \%)$ & $34(1.9 \%)$ \\
\hline No & $2230(97.4 \%)$ & $519(95.4 \%)$ & $1711(98.1 \%)$ \\
\hline \multicolumn{4}{|l|}{ Number of encounters } \\
\hline 1 & $1964(84.3 \%)$ & $519(91.9 \%)$ & $1445(81.9 \%)$ \\
\hline 2 & $260(11.2 \%)$ & $37(6.6 \%)$ & $223(12.6 \%)$ \\
\hline$\geq 3$ & $105(4.5 \%)$ & $9(1.6 \%)$ & $96(5.44 \%)$ \\
\hline \multicolumn{4}{|l|}{ Encounter characteristics } \\
\hline \multicolumn{4}{|l|}{ Diagnosis } \\
\hline Subluxation & $1096(32.5 \%)$ & $545(74.4 \%)$ & $551(20.8 \%)$ \\
\hline Other & $2282(67.6 \%)$ & $188(25.7 \%)$ & $2094(79.2 \%)$ \\
\hline Duration of encounter in minutes, median $(\mathrm{IQR})^{\mathrm{c}}$ & $15(10-25)$ & $10(7-14)$ & $15(10-30)$ \\
\hline Unimodal manipulative treatment & $101(3.0 \%)$ & $91(12.4 \%)$ & $10(0.4 \%)$ \\
\hline Non-musculoskeletal condition as reason for encounter & $30(0.9 \%)$ & $22(3.0 \%)$ & $8(0.3 \%)$ \\
\hline \multicolumn{4}{|l|}{ Patient characteristics } \\
\hline Some activity limitations due to pain $(n=1559)$ & $336(21.6 \%)$ & $60(18.2 \%)$ & $276(22.4 \%)$ \\
\hline Excellent/very good health status $(n=1559)$ & $1253(80.4 \%)$ & $263(79.9 \%)$ & $990(80.5 \%)$ \\
\hline
\end{tabular}


Table 2 (continued)

IQR interquartile range

${ }^{a}$ Unorthodox view of practice defined as viewing vertebral subluxation as an encumbrance to the expression of health that is corrected to benefit patient well-being

${ }^{b}$ Number (\%) of encounters unless otherwise specified

${ }^{\text {C }}$ Do not add up to $100 \%$ due to missing values

Table 3 Effect estimates of the association between unorthodox view of practice ${ }^{a}$ and encounter characteristics $(n=3378$ encounters)

\begin{tabular}{|c|c|c|c|}
\hline & Unadjusted & Age and sex adjusted & Fully adjusted \\
\hline \multicolumn{4}{|l|}{ Subluxation diagnosis ${ }^{\mathrm{b}}$} \\
\hline Unorthodox & OR 108.90 (95\% Cl 8.46-1401.35) & OR $63.33(95 \%$ Cl 4.35-922.72) & OR 63.02 (95\% Cl 4.18-949.07) \\
\hline Orthodox & Reference (1.00) & Reference (1.00) & Reference (1.00) \\
\hline ICC (intercept only: 80.24\%) & $75.25 \%$ & $74.98 \%$ & $75.36 \%$ \\
\hline \multicolumn{4}{|l|}{ Duration of encounter ${ }^{c}$} \\
\hline Unorthodox & $0.57(95 \%$ Cl 0.38-0.84) & 0.57 (95\% Cl 0.38-0.84) & $0.59(95 \%$ Cl $0.41-0.86)$ \\
\hline Orthodox & Reference $(0.00)$ & Reference $(0.00)$ & Reference $(0.00)$ \\
\hline ICC (intercept only: 55.10\%) & $50.67 \%$ & $50.70 \%$ & $48.67 \%$ \\
\hline \multicolumn{4}{|c|}{ Unimodal manipulative treatment $^{d}$} \\
\hline Unorthodox & OR 6.51 (95\% Cl 0.24-179.77) & OR 7.73 (95\% Cl 0.24-247.97) & OR 7.37 (95\% Cl 0.22-243.55) \\
\hline Orthodox & Reference (1.00) & Reference (1.00) & Reference (1.00) \\
\hline ICC (intercept only: 71.63\%) & $72.19 \%$ & $73.01 \%$ & $72.63 \%$ \\
\hline \multicolumn{4}{|c|}{$\begin{array}{l}\text { Non-musculoskeletal condition as } \\
\text { reason for encounter }\end{array}$} \\
\hline Unorthodox & OR 9.66 (2.92-31.92) & OR 9.93 (95\% Cl 2.52-39.20) & OR 16.46 (95\% Cl 3.23-83.96) \\
\hline Orthodox & Reference (1.00) & Reference (1.00) & Reference (1.00) \\
\hline ICC (intercept only: 33.66\%) & $23.09 \%$ & $27.19 \%$ & $31.45 \%$ \\
\hline
\end{tabular}

Cl confidence interval, ICC intraclass correlation coefficientl, OR odds ratio

${ }^{a}$ Unorthodox view of practice defined as viewing vertebral subluxation as an encumbrance to the expression of health that is corrected to benefit patient well-being; all other views of practice considered orthodox

${ }^{b}$ Refers to diagnosis that used the term "subluxation"; model adjusted for age, sex, new patient encounter, extended health insurance as payment, injury related to motor vehicle collision, injury related to workers' compensation, and imaging ordered during encounter

' Refers to duration of patient encounter in minutes (229 encounters excluded due to missing or nonsensical data); based on linear (log-transformed) regression models adjusted for age, sex, new patient encounter, extended health insurance as payment method, injury related to motor vehicle collision, injury related to workers' compensation, and imaging ordered during encounter

${ }^{d}$ Refers to treatment that consisted of manual adjustments or treatment using a chiropractic system only; model adjusted for age, sex, new patient encounter, and extended health insurance as payment method (other variables could not be included because model would not converge)

e Refers to reason for encounter for a non-musculoskeletal condition; model adjusted for age, sex, new patient encounter, and extended health insurance as payment method (other variables could not be included because model would not converge)

to primary analyses (aOR 96.2, 95\% CI 14.2-650.8); chiropractor explained $69.4 \%$ of the variability in the outcome. We could not assess unimodal manipulative treatment due to small numbers. Similar to primary analyses, we found no association between unorthodox view and patient health characteristics.

\section{Discussion}

We found that $80 \%$ of Ontario chiropractors in our study had an orthodox view of practice whereas $20 \%$ of chiropractors had an unorthodox view. Chiropractors with an unorthodox view were associated with treating a non-musculoskeletal reason for encounter and subluxation as diagnosis. Encounters of chiropractors with an unorthodox view were shorter than encounters of those with orthodox views. In the multilevel models, chiropractor level explained a high proportion of the variability in non-musculoskeletal reason for encounter, subluxation as diagnosis, and encounter duration. There was no association between unorthodox view of practice and unimodal manipulative treatment or patient health characteristics.

Our findings that $20 \%$ of chiropractors in Ontario had an unorthodox view is similar to previous studies conducted in Canada and elsewhere. When we reclassified chiropractors to include those predominantly treating subluxations as having an unorthodox view in our sensitivity analysis, we found that $30 \%$ of chiropractors 
Table 4 Odds ratio of the association between unorthodox view of practice ${ }^{a}$ and patient health characteristics $(n=1559)$

\begin{tabular}{llll}
\hline & \multicolumn{2}{l}{ Odds ratio (95\% confidence interval) } & Fully adjusted \\
\cline { 4 - 4 } & Unadjusted & Age and sex adjusted & \\
\hline $\begin{array}{lll}\text { Some activity limitations due to pain } \\
\text { Unorthodox }\end{array}$ & $0.77(0.44-1.36)$ & $0.77(0.42-1.39)$ & $0.76(0.41-1.42)$ \\
Orthodox & Reference $(1.00)$ & Reference $(1.00)$ & Reference $(1.00)$ \\
ICC (intercept only: $8.68 \%)$ & $8.74 \%$ & $9.37 \%$ & $10.01 \%$ \\
Excellent/very good health status ${ }^{c}$ & & & $0.85(0.49-1.49)$ \\
Unorthodox & $0.95(0.56-1.62)$ & $0.91(0.53-1.58)$ & Reference $(1.00)$ \\
Orthodox & Reference $(1.00)$ & Reference $(1.00)$ & $7.74 \%$ \\
ICC (intercept only: $7.25 \%)$ & $7.65 \%$ & $7.93 \%$ & \\
\hline
\end{tabular}

ICC intraclass correlation coefficient

${ }^{a}$ Unorthodox view of practice defined as viewing vertebral subluxation as an encumbrance to the expression of health that is corrected to benefit patient well-being; all other views of practice considered orthodox

${ }^{\mathrm{b}}$ Refers to some activities prevented by pain or discomfort; model adjusted for age, sex, new patient encounter, extended health insurance as payment, injury related to motor vehicle collision, injury related to workers' compensation, and imaging ordered during encounter

${ }^{c}$ Refers to self-rated general health of patient as excellent health/very good, quality of life as very good, and satisfaction with health as very satisfied/satisfied; model adjusted for age, sex, new patient encounter, extended health insurance as payment, injury related to motor vehicle collision, injury related to workers' compensation, and imaging ordered during encounter

would have an unorthodox view; however, the associations remained similar. Previous literature reported that $19 \%$ to $28 \%$ of chiropractors in Canada $[7,14]$ had unorthodox views of practice, and $5 \%$ to $24 \%$ of chiropractors in North America had a focused (unorthodox view) or middle scope (subluxation adjusting combined with other procedures) [15]. Thus, some of these differences may be owing to varied definitions (e.g., focused and middle scope) and that the study surveyed a random sample of chiropractors more broadly in North America in 2004.

Our study results advances the knowledge on patient profiles and treatment approaches among chiropractors with varying views of practice. In their cross-sectional study of a random sample of Canadian chiropractors in 2010, McGregor et al. reported that unorthodox view of practice was associated with non-evidencebased treatment choices (OR 4.2, 95\% CI 2.2-8.0) and non-guidelines-based radiograph use (OR 3.0, 95\% CI 1.7-5.4) [7]. In the study by McGregor et al., nonevidence-based treatment choices included treating allergies, attention deficit hyperactivity disorder, diabetes, multiple sclerosis, cancer, and cystic fibrosis [7]. In our study, we found an association between an unorthodox view of practice and non-musculoskeletal conditions as the reason for encounter. We included visceral (e.g., cancer, immune, endocrine, metabolic, nutritional, cardiovascular, respiratory, gastrointestinal, urinary conditions) and psychological conditions in the list of non-musculoskeletal conditions. Our findings fill an important knowledge gap by providing new evidence on the association between unorthodox view of practice and subluxation as diagnosis and duration of encounter, after accounting for a wide range of potential confounders.

Findings have implications for understanding chiropractic practice and informing shared decision-making between patients and chiropractors. Our study more comprehensively describes the characteristics of patients treated by chiropractors with an unorthodox view and their associated diagnosis and encounter characteristics. This can help guide patient expectations when making informed decisions about their treatment options when seeking care from chiropractors. For example, understanding the type of care provided by chiropractors can facilitate shared decision-making with patients, including enabling patients to make reasoned informed choices and guiding communication on appropriate choices of treatment [23]. Although non-musculoskeletal conditions comprise a small proportion (about 3\%) of patients receiving chiropractic care [17], we found that chiropractors' unorthodox view was associated with treating nonmusculoskeletal conditions. This highlights a potential area for education to guide evidence-based approaches in the management of non-musculoskeletal conditions [24], as well as the understanding that people with musculoskeletal conditions may have non-musculoskeletal comorbidities that impact overall health and well-being [25].

Our study results can also inform interprofessional collaboration between chiropractors and healthcare providers. Previous studies reported that orthopedic 
surgeons and obstetricians in Canada considered diverse views of practice among chiropractors as a barrier to interprofessional collaboration [26-28]. This included issues such as scope of practice associated with the treatment of non-musculoskeletal conditions and nonevidence-based care from chiropractors, as well as the unintended consequence of stigmatization of the profession impacting trustworthiness, collaborative opportunities, and professional identity [29]. Our study found that $20 \%$ of chiropractors had an unorthodox view of practice. Ongoing communication related to diagnosis and types of conditions treated may help to increase collaboration between chiropractors and other healthcare providers to improve patient outcomes. As defined by the World Health Organization, "collaborative practice happens when multiple health workers from different professional backgrounds work together with patients, families, carers, and communities to deliver the highest quality of care across settings" [30]. Describing patient profiles can improve coordinated care between chiropractors and other healthcare providers that is responsive to the needs of the population. We found that an unorthodox view of practice is associated with treating patients with non-musculoskeletal conditions, and care for these patients may include appropriate referrals or co-management with other providers. Identifying treatment approaches among chiropractors can improve access to health interventions and guide appropriate and timely referral that matches the provider's expertise to the needs of patients. Moreover, understanding patient and treatment characteristics can facilitate effective communication, enhanced by team members talking and actively listening while recognizing each other's body of knowledge [30].

\section{Strengths and limitations}

The study has a number of strengths. First, O-COAST data used a number of approaches to minimize measurement error. O-COAST used a valid and reliable method of recording patient encounters in the primary care setting [31]. Data collection forms were modified and pilot tested to be relevant for chiropractic practice in Ontario. The O-COAST data were collected prospectively, including patient encounter-level characteristics recorded during patient encounters, eliminating potential error with recall or approaches involving chart reviews. Second, we used a validated survey question to define chiropractors' view of practice, which has been used in previous studies [7, 21]. We also conducted sensitivity analyses to explore potential misclassification of unorthodox views, which found similar associations to the primary analysis. Third, reasons for encounters and diagnoses were classified based on a validated coding system [32, 33] and involved a quality assurance protocol to ensure reliability across trained coders. Finally, we adjusted for potential confounders and clustering of encounters within chiropractors in the analysis.

The study has limitations. First, despite inviting a random sample of chiropractors to participate, O-COAST had a $36 \%$ response rate and has potential selection bias. This response rate is higher than similar studies assessing patient encounters in general practice (27\% response rate) [34] and chiropractic practice (33\% response rate) [35] in Australia. Second, this is a cross-sectional study, so associations between chiropractors' views of practice and patient health characteristics are based on one time point only. There is also potential for residual confounding; future longitudinal studies in this area that account for a wide range of confounders are needed. Third, the small numbers of encounters for specific non-musculoskeletal conditions within certain categories precluded us from examining them in meaningful ways, and is unlikely to affect our study results. In O-COAST, the proportion of encounters for neurological problems was $0.93 \%$ (95\% CI 0.5-1.8), all types of headaches was $0.68 \%$ (95\% CI $0.3-1.4)$, and concussion was $0.48 \%$ (95\% CI $0.2-1.3)$ [17]. Finally, some study results had wide $95 \%$ confidence intervals due to the smaller number of chiropractor participants and that chiropractor level explained a high proportion of the variability in outcomes.

\section{Conclusions}

Chiropractors with an unorthodox view of practice were associated with treating a non-musculoskeletal reason for encounter, subluxation as diagnosis, and shorter duration of encounter. Chiropractor level explained a high proportion of the variability in these outcomes. Findings have implications for understanding chiropractic practice and informing interprofessional collaboration and future research. Describing the patient profiles and treatment approaches of chiropractors based on view of practice can help guide patient expectations and communication when making informed decisions about their treatment options through shared decision-making. Our findings highlight a potential area for education among chiropractors to guide evidence-based approaches for non-musculoskeletal conditions. In addition, communication related to diagnosis and types of conditions treated may facilitate collaboration between chiropractors and other healthcare providers to improve patient outcomes. 


\section{Abbreviations}

aOR: Adjusted odds ratio; Cl: Confidence interval; IQR: Interquartile range; O-COAST: Ontario Chiropractic Observation and Analysis STudy; OR: Odds ratio; SD: Standard deviation.

\section{Supplementary Information}

The online version contains supplementary material available at https://doi. org/10.1186/s12998-021-00398-x.

Additional file 1. Question assessing chiropractors' view of practice based on study by McGregor et al.

Additional file 2. List of non-musculoskeletal conditions (including visceral and psychological conditions).

Additional file 3. Additional file 3a. Characteristics of chiropractors participating in Ontario Chiropractic Observation and Analysis STudy (O-COAST) by view of chiropractic practice (with unorthodox view classified as predominantly treating subluxations) $(n=40)^{\text {a }}$. Additional File 3b. Characteristics of unique patients in encounters as recorded by participating chiropractors by view of practice (with unorthodox view classified as predominantly treating subluxations) $(n=2332)^{a}$. Additional File 3c. Effect estimates of the association between unorthodox view of practicea and encounter characteristics based on unadjusted, age and sex adjusted, and fully adjusted models in sensitivity analysis ( $n=3378$ encounters). Additional File $\mathbf{3 d}$. Odds ratio of the association between unorthodox view of practicea and patient health characteristics based on unadjusted, age and sex adjusted, and fully adjusted models in sensitivity analysis $(n=1559)$.

Additional file 4. Additional File 4a. Characteristics of chiropractors participating in Ontario Chiropractic Observation and Analysis STudy (O-COAST) by view of chiropractic practice (with unorthodox view classified as predominantly treating subluxation or lifestyle/wellness issues) $(n=40)^{a}$. Additional File $\mathbf{4 b}$. Characteristics of unique patients in encounters as recorded by participating chiropractors by view of practice (with unorthodox view classified as predominantly treating subluxation or lifestyle/wellness issues) $(n=2332)^{\mathrm{a}}$. Additional File 4c. Effect estimates of the association between unorthodox view of practicea and encounter characteristics based on unadjusted, age and sex adjusted, and fully adjusted models in sensitivity analysis ( $n=3378$ encounters). Additional File $4 \mathbf{d}$. Odds ratio of the association between unorthodox view of practicea and patient health characteristics based on unadjusted, age and sex adjusted, and fully adjusted models in sensitivity analysis $(n=1559)$.

\section{Acknowledgements}

We gratefully thank the chiropractor and patient participants for their efforts in participating in the Ontario Chiropractic Observation and Analysis STudy (O-COAST).

\section{Authors' contributions}

JJW: conceptualization, methodology, formal analysis, and writing-original draft, review and editing. SHJ: conceptualization, methodology, formal analysis, and writing - review and editing. AEB: conceptualization, methodology, and writing - review and editing. SDF: conceptualization, methodology, and writing - review and editing. SAM: conceptualization, methodology, and writing-review and editing.

\section{Funding}

The Ontario Chiropractic Association and the Senate Advisory Research Committee, Queen's University funded the O-COAST study. The Ontario Chiropractic Association provided general advice about the design of the project, but was not involved in the collection of data, data analysis, interpretation of data or drafting of the manuscript.

\section{Availability of data and materials}

The datasets generated and/or analysed during the current study are not publicly available due to privacy restrictions but are available from the corresponding author on reasonable request.

\section{Declarations}

\section{Ethics approval and consent to participate}

All methods were performed in accordance with the Declaration of Helsinki. This project has been approved by the Research Ethics Board at the Canadian Memorial Chiropractic College (REB \#1404X03). Informed consent to participate in the study was obtained from all participants.

\section{Consent for publication}

Not applicable.

\section{Competing interests}

Dr. Wong is supported by a Canadian Institutes of Health Research (CIHR) Frederick Banting and Charles Best Canada Graduate Scholarships Doctoral Award and the tuition assistance program at the Canadian Memorial Chiropractic College, and reports grants from Canadian Chiropractic Research Foundation outside the submitted work. Dr. Mior reports grants from Ontario Chiropractic Association during the conduct of the study, and grants from Canadian Chiropractic Association outside the submitted work. Dr. Hogg-Johnson reports grants from Canadian Chiropractic Association during the conduct of the study, and grants from Canadian Chiropractic Research Foundation outside the submitted work. Dr. French reports grants from Ontario Chiropractic Association during the conduct of the study. The remaining authors declare that they have no competing interests.

\section{Author details}

${ }^{1}$ Institute for Disability and Rehabilitation Research, Ontario Tech University and Canadian Memorial Chiropractic College, 2000 Simcoe Street North, Oshawa, ON L1G 0C5, Canada. ${ }^{2}$ Dalla Lana School of Public Health, University of Toronto, 155 College Street, 6th Floor, Toronto, ON M5T 3M7, Canada. ${ }^{3}$ Graduate Studies, Canadian Memorial Chiropractic College, 6100 Leslie Street, Toronto, ON M2H 3J1, Canada. ${ }^{4}$ Department of Research and Innovation, Canadian Memorial Chiropractic College, 6100 Leslie Street, Toronto, ON M2H 3J1, Canada. ${ }^{5}$ School of Physical and Occupational Therapy, Faculty of Medicine and Health Sciences, McGill University, 3654 Prom Sir-William-Osler, Montreal, QC H3G 1Y5, Canada. ${ }^{6}$ Département Chiropratique, Université du Québec à Trois-Rivières, 3351 Boulevard des Forges, Trois-Rivières, QC G8Z 4M3, Canada. ${ }^{7}$ Department of Chiropractic, Faculty of Medicine, Health and Human Sciences, Macquarie University, Level 3, 17 Wally's Walk, North Ryde, NSW 2019, Australia.

Received: 21 June 2021 Accepted: 15 September 2021

Published online: 28 September 2021

\section{References}

1. World Health Organization. World Health Organization (WHO) guidelines on basic training and safety in chiropractic. 2005. Available at: https:// apps.who.int/iris/handle/10665/43352. Accessed Mar 1, 2021

2. Frass M, Strassl RP, Friehs H, Müllner M, Kundi M, Kaye AD. Use and acceptance of complementary and alternative medicine among the general population and medical personnel: a systematic review. Ochsner J. 2012;12(1):45-56.

3. CAMDOC Alliance: the regulatory status of complementary and alternative medicine for medical doctors in Europe. 2010. Available at: http:// www.camdoc.eu/Pdf/CAMDOCRegulatoryStatus8_10.pdf. Accessed May 1,2021

4. World Federation of Chiropractic. The current status of the chiropractic profession. Report to the World Health Organization from the World Federation of Chiropractic, 2012. Available at: https://www.wfc.org/website/ images/wfc/WHO_Submission-Final_Jan2013.pdf. Accessed May 1, 2021

5. Beliveau PJH, Wong JJ, Sutton DA, Simon NB, Bussières AE, Mior SA, et al. The chiropractic profession: a scoping review of utilization rates, reasons for seeking care, patient profiles, and care provided. Chiropr Man Therap. 2017:25:35.

6. Mior SA, Laporte A. Economic and resource status of the chiropractic profession in Ontario, Canada: a challenge or an opportunity. J Manip Physiol Ther. 2008;31(2):104-14. 
7. McGregor M, Puhl AA, Reinhart C, Injeyan HS, Soave D. Differentiating intraprofessional attitudes toward paradigms in health care delivery among chiropractic factions: results from a randomly sampled survey. BMC Complement Altern Med. 2014;14:51

8. Hannon SM. Objective physiologic changes and associated health benefits of chiropractic adjustments in asymptomatic subjects: a review of the literature. J Vertebr Subluxation Res. 2004;26:1-9.

9. Rome P, Waterhouse J. Evidence informed vertebral subluxation - a diagnostic and clinical imperative. J Philos Princ Pract Chiropr. 2019:12-34.

10. Russell D. The assessment and correction of vertebral subluxation is central to chiropractic practice : is there a gap in the clinical evidence? J Contemp Chiropr. 2019;2:4-17.

11. Bussières AE, Al Zoubi F, Stuber K, French SD, Boruff J, Corrigan J, et al. Evidence-based practice, research utilization, and knowledge translation in chiropractic: a scoping review. BMC Complement Altern Med. 2016;16:216.

12. Schneider MJ, Evans R, Haas M, Leach M, Hawk C, Long C, et al. US chiropractors' attitudes, skills and use of evidence-based practice: a crosssectional national survey. Chiropr Man Therap. 2015;23:16.

13. Leboeuf-Yde C, Innes SI, Young KJ, Kawchuk GN, Hartvigsen J. Chiropractic, one big unhappy family: better together or apart? Chiropr Man Therap. 2019;27:4.

14. Biggs L, Mierau D, Hay D. Measuring philosophy: a philosophy index. J Can Chiropr Assoc. 2002;46(3):173.

15. McDonald WP, Durkin KF, Pfefer M, editors. How chiropractors think and practice: the survey of North American chiropractors. Semin Integr Med; 2004. Elsevier.

16. Villanueva-Russell Y. Caught in the crosshairs: identity and cultural authority within chiropractic. Soc Sci Med. 2011;72(11):1826-37.

17. Mior S, Wong J, Sutton D, Beliveau PJH, Bussières A, Hogg-Johnson S, et al. Understanding patient profiles and characteristics of current chiropractic practice: a cross-sectional Ontario Chiropractic Observation and Analysis STudy (O-COAST). BMJ Open. 2019;9(8):e029851.

18. STROBE Statement. Strengthening the reporting of observational studies in epidemiology. STROBE checklists: Checklist for cross-sectional studies, 2007. Available at: https://www.strobe-statement.org/index.php?id=avail able-checklists. Accessed May 1, 2021

19. Statistics Canada. Population estimates on July 1st, by age and sex. 2020. Available at: https://www150.statcan.gc.ca/t1/tbl1/en/tv.action?pid=17100 00501. Aaccessed May 1, 2021

20. College of Chiropractors of Ontario. Who are Chiropractors. 2018. Available at: https://cco.on.ca/members-of-the-public/who-are-chiropractors/. Accessed May 1,2021

21. Puhl AA, Reinhart CJ, Doan JB, McGregor M, Injeyan HS. Relationship between chiropractic teaching institutions and practice characteristics among Canadian doctors of chiropractic: a random sample survey. J Manip Physiol Ther. 2014;37(9):709-18.
22. Schneider M, Murphy D, Hartvigsen J. Spine care as a framework for the chiropractic identity. J Chiropr Humanit. 2016;23(1):14-21.

23. Stiggelbout AM, Van der Weijden T, De Wit MP, Frosch D, Légaré F, Montor VM, et al. Shared decision making: really putting patients at the centre of healthcare. BMJ. 2012;344:e256

24. Côté P, Hartvigsen J, Axén I, Leboeuf-Yde C, Corso M, Shearer H, et al. The global summit on the efficacy and effectiveness of spinal manipulative therapy for the prevention and treatment of non-musculoskeletal disorders: a systematic review of the literature. Chiropr Man Therap. 2021;29(1):8.

25. Hartvigsen J, Natvig B, Ferreira M. Is it all about a pain in the back? Best Pract Res Clin Rheumatol. 2013;27(5):613-23.

26. Busse JW, Jacobs C, Ngo T, Rodine R, Torrance D, Jim J, et al. Attitudes toward chiropractic: a survey of North American orthopedic surgeons. Spine (Phila Pa 1976). 2009;34(25):2818-25.

27. Busse JW, Jim J, Jacobs C, Ngo T, Rodine R, Torrance D, et al. Attitudes towards chiropractic: an analysis of written comments from a survey of north american orthopaedic surgeons. Chiropr Man Therap. 2011;19(1):25.

28. Weis CA, Stuber K, Barrett J, Greco A, Kipershlak A, Glenn T, et al. Attitudes toward chiropractic: a survey of Canadian obstetricians. J Evid Based Complementary Altern Med. 2016;21(2):92-104.

29. Triano JJ, McGregor M. Core and complementary chiropractic: lowering barriers to patient utilization of services. J Chiropr Humanit. 2016;23(1):1-13.

30. World Health Organization. Framework for action on interprofessional education \& collaborative practice. 2010. Available at: https://www.who.int/publi cations/i/item/framework-for-action-on-interprofessional-education-colla borative-practice. Accessed Aug 10, 2021

31. Britt H. A measure of the validity of the International Classification of Primary Care in the classification of reasons for encounter. J Innovat Health Inform. 1997:6(2):8-12.

32. Charity MJ, French SD, Forsdike K, Britt H, Polus B, Gunn J. Extending ICPC-2 PLUS terminology to develop a classification system specific for the study of chiropractic encounters. Chiropr Man Therap. 2013;21(1):4.

33. Classification Committee World Organization of Family Doctors (WICC). ICPC-2: International classification of primary care. 2nd ed. Oxford: Oxford University Press, 1998.

34. Britt $\mathrm{H}$, Miller $\mathrm{G}$, Henderson J, et al. General practice activity in Australia 2011-12. general practice series no.31. Sydney: Sydney University Press, 2012.

35. French SD, Charity MJ, Forsdike K, Gunn JM, Polus BI, Walker BF, et al. Chiropractic Observation and Analysis Study (COAST): providing an understanding of current chiropractic practice. Med J Aust. 2013;199(10):687-91.

\section{Publisher's Note}

Springer Nature remains neutral with regard to jurisdictional claims in published maps and institutional affiliations.

Ready to submit your research? Choose BMC and benefit from:

- fast, convenient online submission

- thorough peer review by experienced researchers in your field

- rapid publication on acceptance

- support for research data, including large and complex data types

- gold Open Access which fosters wider collaboration and increased citations

- maximum visibility for your research: over 100M website views per year

At BMC, research is always in progress.

Learn more biomedcentral.com/submissions 